\title{
Energy Security and Climate Change: India's Responses to the Challenges
}

\author{
C. Vinodan \& Anju Lis Kurian \\ School of International Relations and Politics \\ Mahatma Gandhi University, Kottayam, Kerala, India \\ Corresponding author:vinodan.c@gmail.com \\ DOI: https://doi.org/10.32890/jis2015.11.3
}

\begin{abstract}
Energy is the prominent navigator of climate change as it contributes to most of the greenhouse gases (GHGs) and the burning of fossil fuels are the foremost sources of GHG emissions. Climate change is a major challenge for developing countries like India that face large scale climate variability and are exposed to enhanced risks from climate change. Few countries in the world are as vulnerable to the effects of climate change as India is with its vast population that is dependent on the growth of its agrarian economy, its expansive coastal areas and the Himalayan region and islands. The vulnerabilities of climate change and energy insecurity are directing a global changeover towards a low carbon and sustainable energy path. In the UNFCC, India has cleared its stand that it would not make any commitments to trim down its GHG emissions as it has one of the least per capita emissions and in the first place the developed world is responsible for the dilemma and the developing world requires the carbon space to spring up. But by being a responsible and progressive member of the international community, India demonstrated the flexibility towards the endeavours to trim down climate change causalities. India is endowed with diverse natural resources such as solar, wind, water and biomass; these are the promising resources to meet up the energy requirements of the coming years. The present paper attempts to analyse the linkages between climate change and energy security. The paper also aims to project India's response to the global climate regime. The paper argues that the problems of climate change and energy security are the major obstacles for India's energy policy while they open gargantuan opportunities to shift its people to cleaner energy trajectories and know-how in the long term.
\end{abstract}

Keywords: Energy security, climate change, UNFCCC, greenhouse gases, NAPCC, renewable energy sources.

\section{Introduction}

The present global scenario is typified with rigorous competition for capital, augmented resource nationalism, a phase of volatile oil prices and an amplified linkage between energy security and climate change concerns. Climate change as a global environmental challenge has repercussions on food production, water supply, health, energy and so forth ${ }^{1}$. The 
United Nations Framework Convention on Climate Change (UNFCCC) has defined the term 'climate change' as a change of climate which is attributed directly or indirectly to human activity that alters the composition of the global atmosphere and which is in addition to natural climate variability observed over comparable time periods. The key features of climate change comprises increase in average global temperature, ice cap melting, variation in precipitation, and rise in ocean temperature contributing to sea level go up etc ${ }^{2}$. Energy is the foremost navigator of climate change as it contributes to most of the green house gases $(\mathrm{GHGs})^{3}$ and the burning of fossil fuels are the principal sources of GHG emissions. In the observation of International Energy Agency (IEA) among the various human activities, the utilization of energy represents the leading source of GHG emanations ${ }^{4}$. As per the data anthropogenic GHG releases have grown since pre-industrial times, with an augment of 70 percent between 1970 and 2004. Along with the giving out of natural GHGs like carbon dioxide, methane and nitrous oxide the enhanced emission also consist of many man-made gases such as chlorofluorocarbons (CFCs), hydrofluorocarbons (HFCs), perfluorocarbons (PFCs) and sulphur hexafluoride (SF6). The increase in the emission of these GHGs causes the enhanced greenhouse effect that tends to increase the surface temperatures and the rise in the average temperature of the Earth is called global warming. This phenomenon leads to unprecedented climate changes on a global scale which threatens the ecosystems of the entire world ${ }^{5}$. The present paper is an attempt to analyse the linkages between climate change and energy security. The paper also aims to project India's response to the global climate regime. The paper argues that the problems of climate change and energy security are the major obstacles for India's energy policy while they open gargantuan opportunities to shift its people to cleaner energy trajectories and know-how in the long term. Climate change is an important energy security issue on the pretext that direct flooding and natural disasters can smash up power plants and transmission lines, interrupt the delivery of imported energy fuels, and demolish crops for biofuels. These effects can repercussions in the income base of developing countries and heighten their government debts these further complicates the endeavours of a resonant energy policy making ${ }^{6}$. Thus the indispensable efforts to deal with the climate change impasse in the developing countries are on one hand the mitigation of GHG emissions and on the other hand the building up of adaptive capacities. It is essential to cope up with the unfavourable impacts of climate change on diverse sectors of society as well as economy that should be enabled and supported with technology as well as finance? The threat of climate change has been one of the primary concerns on the global community, ever since its disastrous impacts were brought to the notice of the public at large. Extreme weather phenomena such as floods, droughts, heat waves and cyclones, experienced in different parts of our globe, are among the far reaching consequences of climate change, giving us a bitter foretaste of what worse may come in the near future. The link between climate change and human survival is now as clear as ever.Climate change has a multifaceted nature and cut across a spectrum of issues so by taking in hand the issue India can benefit both domestically and internationally. Besides India's ambitions to play strategically decisive role in the global scenario as well as handle with domestically significant concerns like energy security and energy access band together the issue of climate change ${ }^{8}$. The increased pressure from international community to limit emissions of greenhouse gases 
(GHG) and to trim down the carbon footprint creates a major challenge to the nation's energy security. At present India is one of the lowest emissions per capita while as the energy consumption enhances the emissions will also enlarge commensurately. India's energy mix (Figure 1) is dominated by fossil fuels, with 68 percent of total power generated from coal in addition large scale reliance on imported oil as well as coal, large peak power as well as energy deficits together with high energy intensity put forward severe challenges to climate change and energy security. Due to these factors the carbon dioxide giving out is estimated to rise from 0.9 billion tonnes to 5.8 billion tonnes in 2031. Therefore India has set an objective of achieving 20 percent diminutions in $\mathrm{CO}_{2}$ intensity by 2020 as compared to 2005 levels $^{9 \& 10}$.

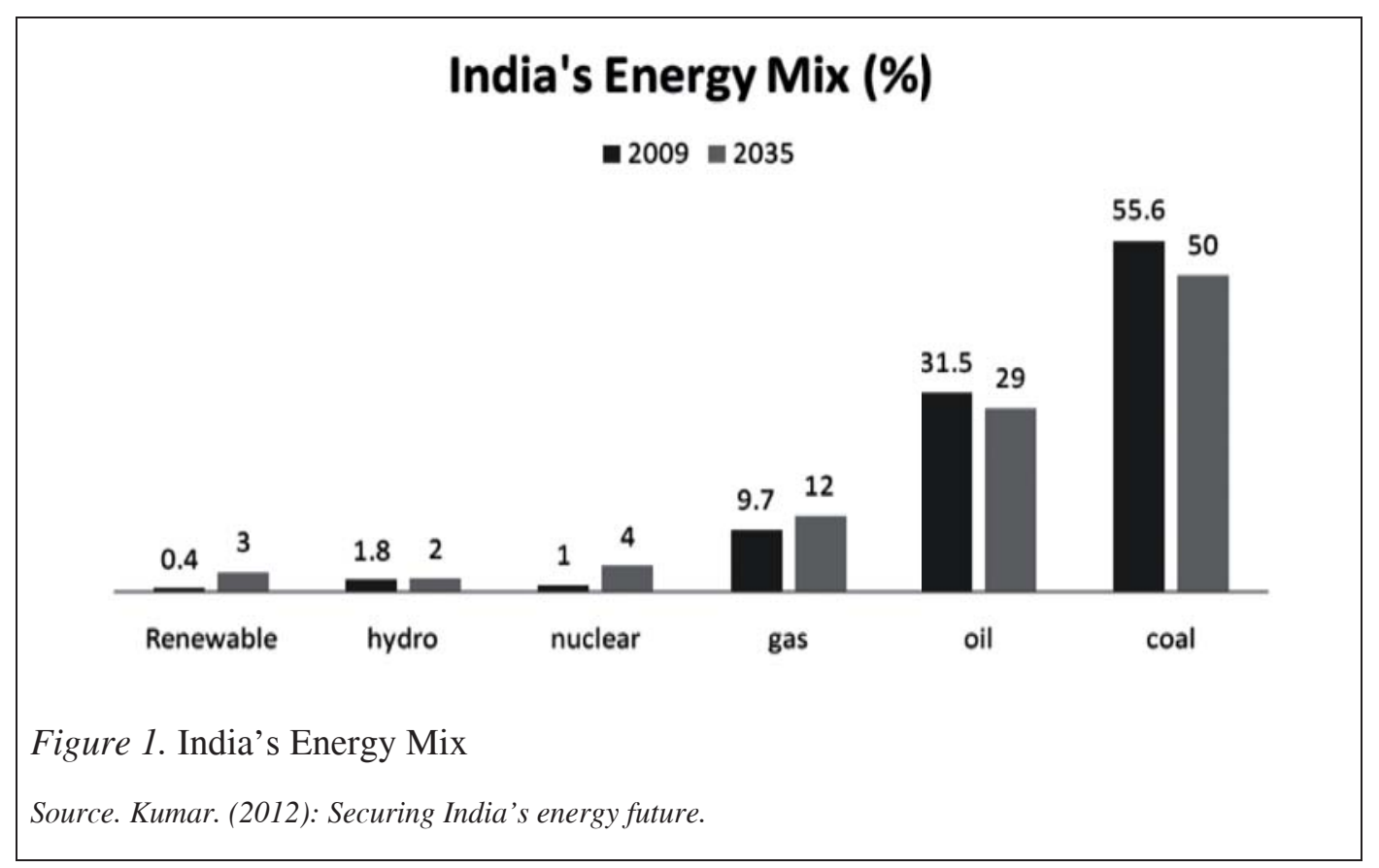

The apprehensions of climate change and energy security are navigating a global changeover towards a low carbon and sustainable energy path ${ }^{11}$. Clean energy is decisive for advancing economic development in an environmentally attuned way ${ }^{12}$. In this century, the issue of climate change comes into every decision making of governments especially in all matters relevant to energy policies because our over reliance on fossil fuels for energy is an alarming challenge facing humanity. Each and every nation requires a proactive as well as avant-garde energy policy and a restructuring of economies. It will increasingly facilitate the smooth transition from the existing unsustainable fossil fuel energy structure to an ecologically and economically sustainable arrangement based on alternative energy sources in order to decarbonise our energy system. Fossil fuels are the most heavily subsidised energy sources in an estimated USD 180 to 200 billion per year on a worldwide scale. Therefore, those who disperse the bulk of energy subsidies result in a lower price for fossil fuels to end users for 
consumption which increases carbon-dioxide and other greenhouse gas emissions. So an energy revolution is needed to reform the national energy policies with a focus on efficient and sustainable energy pricing because an 'efficient energy pricing is the inescapable principle on which rests the future of sustainable economic growth" ${ }^{13}$.

At the international level, the United Nations Framework Convention on Climate Change (UNFCCC) adopted at the Rio Earth Summit in 1992 and entered into force in 1994. It aimed at accomplishing stabilization of greenhouse gas concentrations in the atmosphere at a level that would prevent dangerous anthropogenic interference with the climate system ${ }^{14}$. This is essential to realize within a time frame: to permit the ecosystems to adapt naturally to climate change, to make sure that the food production is not to be endangered and to facilitate the economic development to ensue in a sustainable means. On the other side this was a decisive move towards putting in place the institutions and processes for the governments across the world to take coordinated and effective action ${ }^{15}$. The Convention has distinguished the commitments and responsibilities of the signatories according to their respective capabilities, economic structures, resource capacities and on the basis of the principle of 'equity' that is at the centre of climate change debate. Taking into account of the historical responsibilities for the developed countries the Convention laid legally binding commitments on them. The commitments include the diminution of GHG emissions with reference to 1990 levels and the provision of financial and technological support to developing countries so as to enable them to assume voluntary mitigation and adaption measures. At the same time the Convention makes out that economic as well as social development and poverty obliteration are the 'first and overriding priorities' of the developing countries. Though the world as a whole face the challenge to limit and cut emissions and to adapt to climate change, the Convention succeeded in handing over varying commitments on developed and developing countries depending upon the common but differentiated responsibilities of countries to take action ${ }^{16}$.

The accomplishment of a global regime based on the principle of equity and common but differentiated responsibility was the need of the hour to grapple with the GHG discharges whereby to limit the climate change reverberations. However, from its inception onwards the international negotiations have been witnessing divergences between developing and developed countries in the matters of emission cuts, financing, technology transfer and other related issues. On the one hand the EU is adamant that the developing countries, especially emerging economies such as India, China, Brazil and South Africa, should do more to reduce the global emissions. On the other hand, emerging economies like India argues that the global regime should be founded on the principles of equity ${ }^{17}$. The developed countries constantly attempts to get away from their larger responsibility of the huge share of historical as well as current share of the giving out of GHGs and their greater capability than the developing countries to face the costs of global response to climate change challenge. Instead of meeting their own obligations, the developed countries are strives to hand over the burden on developing countries but they give priorities on their economic 
growth. So this contention is to reciprocally tackled, otherwise global response towards finding a sustainable way out to the troubles of climate change will be hampered. On 15 May 2015, China and India issued a joint statement that insisted developed countries to formulate large emissions cuts before 2020 and provide US\$100 billion per year in aid by 2020 to assist poor countries to adapt to warming and decrease emissions ${ }^{18}$. It is perceptible that quantified emission cutback commitments from the developed countries can only attain genuine reduction in green house gas giving off.

In 1997, as part of UNFCCC's concerted international action the Kyoto Protocol has adopted with a legally binding quantitative time-bound target for developed countries. The Kyoto Protocol's target was to reduce overall emissions individually or jointly by an average of 5 percent below 1990 levels during the first commitment period of 2008 to 2012. The Protocol has seen as one of the noteworthy instrument in the reduction of carbon emissions of the developed countries. Up till now, USA- the world's leading emitter of greenhouse gases, has not ratified it which has raised serious misgivings in the efficacy of this protocol ${ }^{19 \& 20}$. By recognizing the fact that depending on national policies alone to meet the target could be arduous, the Protocol put forward substantial flexibility via three mechanisms: Clean Development Mechanism (CDM), Joint Implementation (JI), and Emissions Trading (ET). The CDM enables the industrialized countries to finance mitigation projects in developing countries responsible to their sustainable development. So they can use the emissions credits obtained from such projects to fulfil their commitments under Kyoto Protocol. JI opens the space for industrialized countries to acquire credit through financially supporting projects in other industrialized countries ${ }^{21}$. ET permits countries that exceed their emissions limits to buy unused quotas from countries whose emissions are under target levels and those that emit less can sell their unused quotas ${ }^{22}$. It is perceived that imposing a carbon price through tax, trading or regulation is a necessary basis for climate change strategy. In this context, emitters are visibly charged with the social cost of their deeds and lead individuals as well as businesses to get away from high-carbon goods and services in addition to invest in lowcarbon alternatives ${ }^{23}$.

The worldwide apprehension about climate change has altered the classical approach of looking at energy security mainly in terms of demand and supply of hydrocarbons. The main human-induced dimension of climate change called global warming is the function of the stock of carbon dioxide in the atmosphere ${ }^{24}$ and developing countries are particularly vulnerable to this occurrence. It is generally recognised that when compared to developed countries the impact of climate variability and change badly affects developing countries. It is on the pretext that in developing countries the ecological environments are brittle, the susceptibility of economic systems to risks is soaring and the low income levels of most populace hinder their capacity to survive. The initial conditions of each and every country with respect to its climatic conditions, socio-economic surroundings and growth panorama will also partially determine the magnitude of social, economic and environmental consequences of climate change ${ }^{25}$. 


\section{India's Response to Climate Change and Energy Security}

India has agreed to communicate information about the implementation of the United Nations Framework Convention on Climate Change (UNFCCC) in accordance with the obligations cast on parties to the Convention. At the same time India has maintained a consistent position that it will be on the basis of common but differentiated responsibilities and respective capabilities and their specific regional and national development priorities, objectives and circumstances. Even though the components of information presented in the communication incorporates a national inventory of anthropogenic emissions by sources and removals by sinks of all Green House Gases, a general description of steps taken to implement the Convention including an assessment of impacts and vulnerability and any other relevant information ${ }^{26}$. In the UNFCC, India has cleared its stand that it would not make any commitments to trim down its GHG emissions as it has one of the least per capita emissions and in the first place the developed world is responsible for the dilemma and the developing world requires the carbon space to spring up. But as a responsible country India has taken some firm measures in the reduction of GHG emanations and the Government has a domestic mitigation goal of reducing emissions intensity of Gross Domestic Product (GDP) near 20-25 percent by 2020 vis-à-vis 2005 level. It is obscure that the upgradation of energy infrastructure, renewable energy infrastructure investments, policies that promote energy security etc in various sectors of the Indian economy offers prospects for GHG releases diminution ${ }^{27}$. The developing countries like India find it difficult to sustain their argument of responsibility for addressing global climate change risks that is more obligations on the developed countries for the time being. The global regime could share out burdens on the basis of past emissions nevertheless it cannot undo the past and can only hold back upcoming emissions, the majority of which will come from emerging economies in $\mathrm{Asia}^{28}$. According to the US Energy Information Administration in 2003 carbon dioxide from energy use per capita per year were O.9 tonne in India and 2.7 tonnes in China as against around 8 tonnes in Europe and nearly 20 tonnes in USA. Thus the developing countries of Asia can justifiably point to their low per capita emissions and can charge historical as well as present culpability of the problem on the developed countries ${ }^{29}$. However, India's per capita emission is one of the lowest in the world the absolute GHG emission is raising on a yearly basis ${ }^{30}$.

As the second largest populous country of the globe ${ }^{31}$ with around 700 million rural population, the projected climate change forms rigorous repercussions on Indian economy and society. It is because the nation primarily depends upon climate sensitive sectors such as agriculture, forests as well as fisheries and natural resources such as water, biodiversity, mangroves, coastal zones, grasslands for their survival and livelihoods in rural areas. Even more the adaptative potential of dry land farmers, forest dwellers, fisher folk and nomadic shepherds is extremely pathetic. So there is the possibility that the climate change may blow the natural ecosystems as well as socio-economic systems of rural India ${ }^{32}$. The destruction of natural ecosystems is expected to have substantial undesirable effects mainly on agriculture 
on which 58 percent of the inhabitants still depends for livelihood, water storage in the Himalayan glaciers which are the source of major rivers and groundwater recharge, sealevel rise, and threats to a long coastline and habitations. Besides it will cause amplified frequency of extreme events such as floods and droughts these in turn intensify food security struggles and water security ${ }^{33}$. A number of states in India for example Maharashtra are projected to endure greater drought which may likely to wipe out 30 percent of food production inducing \$7 billion in damages amid 15 million small and marginal farmers. Altogether in India farmers and fishers have to migrate from coastal areas as sea levels rise and to deal with heat waves, lowering crop output and to manage declining water tables from saltwater intrusion ${ }^{34 \& 35}$. As said by International Development the impacts of climate change, among other things are the following: 1) accelerated river bank erosion, saltwater intrusion, crop losses, and floods; 2) more frequent and intense droughts crippling yields and reducing national foreign exchange and lowering incomes for low-wage workers; 3 ) higher sea levels inundating half of the agricultural lands causing food insecurity; 4) increased ocean flooding and storm surges inundating farmland affecting the livelihoods of people; and 5) intensified floods placing people at risk and causing economic damages. Their study has concluded with the opinion that coastal regions will have more land endangered, more people injured, and more economic spoil from rising sea levels than any other part of the earth ${ }^{36}$.

It is well aware that the effects of climate change are far-reaching so as no country can sit on the sidelines. India is having 17 percent of the world's total population but contributes only 4 percent of the overall global greenhouse gas emissions (Figure 2) compared to 30 percent of the US and 25 percent of the EU members. In addition, the per capita GHG emissions in India are lower at only $1.1 \mathrm{Mt} \mathrm{CO}_{2}$ around 23 percent of the global average as against the per capita emissions of $22 \mathrm{MtCO}_{2}$ in US and $15 \mathrm{MtCO}_{2}$ in $\mathrm{EU}^{37}$. This decrease of GHG emanations is on the backdrop of the reality that approximately 55 percent of India's population still does not have access to commercial energy. In 2007, the GHG emissions from energy, industry, agriculture, and waste sectors make up 58 percent, 22 percent, 17 percent, and 3 percent of net $\mathrm{CO}_{2}$ eq. emissions respectively. The total emission of green house gases is leap to rise in India through the projects with the intention of fulfilling the demands of growing standards of living and facilitating access to commercial energy to those lacking $i^{38}$. As one look into the energy profile of India will come across the fact that India's energy is deficient to meet its needs. Just about 600 million Indians are short of electricity and 700 million people depend on traditional fuels. Around 650 units of electricity is the per capita consumption per annum that is well below the global average. Its overall installed electrical generating ability is less than 150 gigawatts $(\mathrm{GW})$, directing to estimated shortages of almost 10 percent in terms of energy ${ }^{39}$. In this context, to supply its population with a realistic level of $21^{\text {st }}$ century opportunities India would need to generate $0.5 \mathrm{~kW}$ per person of electric power ${ }^{40}$. India imports 70 percent of its oil, 11 percent of its coal, and 17 percent of its natural gas to tackle its ever growing energy demands ${ }^{41}$. 


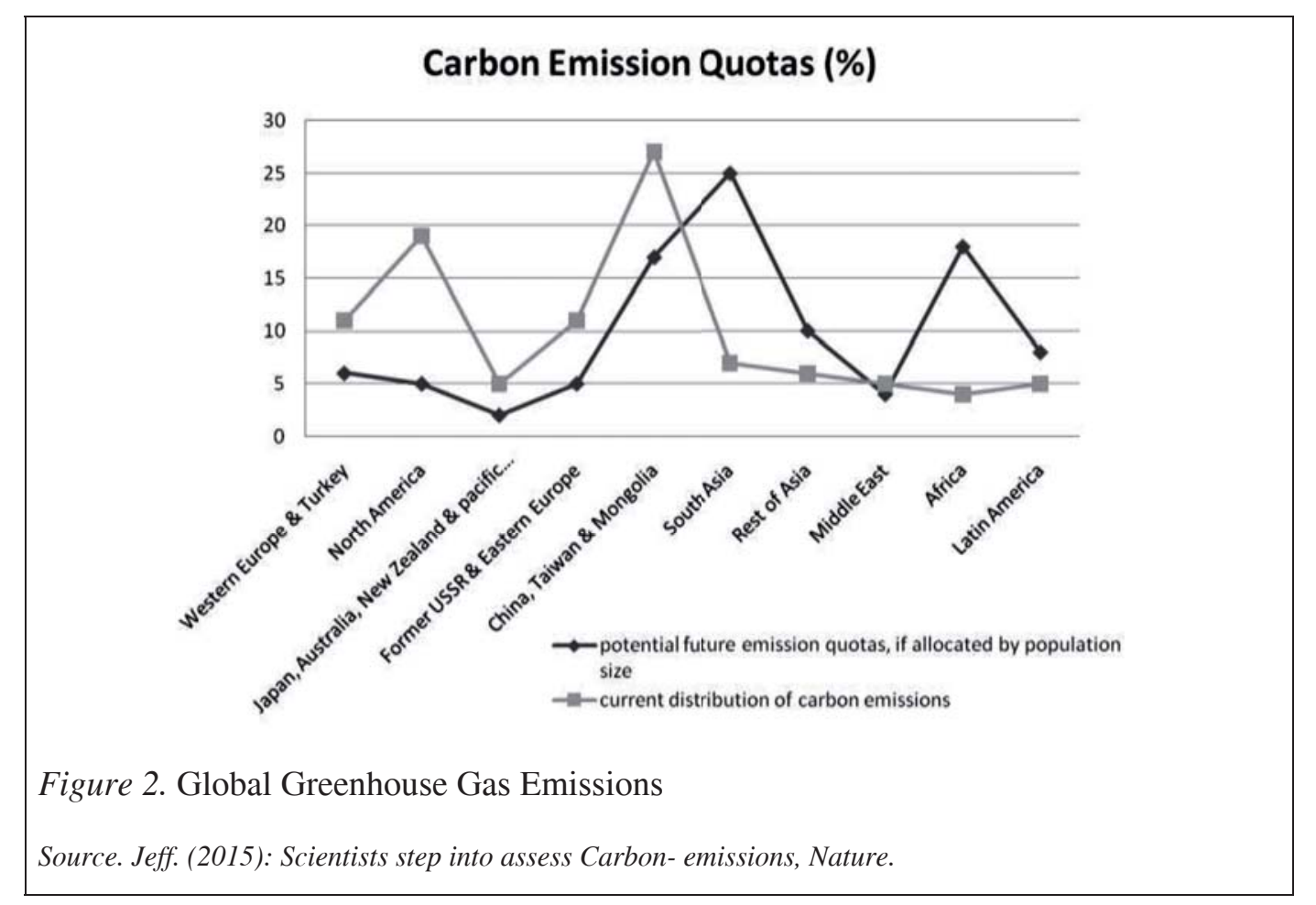

The Integrated Energy Policy (IEP) of 2006 is the first comprehensive energy policy of the Indian government. It proposes long-standing goals for the entire energy sector in an integrated and comprehensive manner. It also considered the problems of climate change and increasing environmental degradation in India ${ }^{42}$. As stated by the Integrated Energy Policy (IEP), energy requirements to deal with India's development targets has to go from 327 million tons of oil equivalent (mtoe) in 2003-2004 to as high as 1858 mtoe in 2031. India's imported fossil fuel reliance is increasing due to its over dependence on hydrocarbons together with a short domestic reserve base for oil as well as the low resource base for coal than projected in the earlier. It is anticipated that by 2031-2032 India's contribution to the global supply of fossil fuels is between 3.7 and 10.9 percent. For India the potential irregularities of supply and affordability become key energy security concerns along with constrained supplies as well as intensifying demands from other countries in the global market of fossil fuels. As a result India needs to increase its share of fossil fuels in the global market to get rid of its energy security alarms. Above all, the emerging carbon constraint poses a crucial challenge to India's capacity to manoeuvre on the energy front particularly since India have to depend profoundly on hydrocarbons for the next 20 years ${ }^{43 \& 44}$.

The Indian political leadership regarded energy security as the capability to 'supply lifeline energy to all our citizens as well as meet their effective demand for safe and convenient energy at affordable $\operatorname{cost}{ }^{45}$. In India, energy security has two diverse but intertwined characteristics. The former relates to the necessity to attain improved distribution and utilization of energy 
by people predominantly in rural India so that a nominal amount of commercial energy is obtainable for everyone. The latter is connected to the need to find ways for satisfying the mounting demand for energy, which would prop up at least 8 percent growth in the country's GDP, which is indispensable to steer industrial growth and ameliorate the standards of living of the common people. Therefore, the country is faced by formidable challenge with regard to meet its national development objectives and addressing national concerns on energy security as well as global concerns on climate change ${ }^{46}$. Generally, the Indian government is pursuing three energy policy objectives: Firstly, access to energy is the primary target in India's energy policy making because nearly one-fourth of the population lacks the right to use electricity. This means ensuring the supply of sufficient and dependable energy to the Indian population in the midst of mounting energy requirements reinforced by economic growth. Secondly, energy security in the present circumstances is driven by growing reliance on imported fuels, which is essential to satisfy the India's massive energy demand. Augmented import dependence of the country poses greater geopolitical risks and threats of international price volatility. Finally, India is devoted to the mitigation of climate change even though defeating energy poverty and guaranteeing economic and social development continues as the upmost priorities ${ }^{47}$.

The industrial production not only impelled India's economic growth but also averted the country from lowering its energy intensity which is the energy consumption per dollar of gross domestic product. Simultaneously the prolonged dependence on coal for electricity generation indicates that India has one of the utmost levels of carbon intensity which are the carbon emissions per dollar of gross domestic product. Whereas the Indian government is ever more turning to renewable energy to meet the country's mounting energy consumption requirements. Although the government endorsed plans to increase the use of more environmentally-friendly energy sources like solar power and hydroelectricity, the environmental prospect for India seems unenthusiastic ${ }^{48}$. As fast as the scientific evidence of global warming accumulates the restraints on fossil fuel based development in India will rise in tandem with international determination to tone down climate change. India's ability to access and buy fossil fuels in the world market will determine the balance between its development goals and climate change mitigation strategies. India faces a stiff competition in the global energy market owing to the size of its needs and opposition from China and other rapidly developing countries, US, Europe and the Asian Tigers in conjunction with the cost-effectiveness plus the timescale within which the world adopts alternate technologies ${ }^{49}$. Simultaneously the energy intensity of India's output has revealed a declining tendency as a result of advances in energy efficiency, autonomous technological changes and economical utilization of energy ${ }^{50}$. In comparison with global trends India's future emissions will be negligible thus its transition from the fossil fuel-intensive energy path to a sustainable plus alternative energy sources may not formulate a great difference to the trajectory of climate change. Even though such a changeover will have significant repercussions for its energy security imperative because dependence on imported oil carries economic risks linked to oil price volatility and the costs of disruption in international oil supplies as well as the geopolitical threats connected with factors beyond its control 
stemming from a high dependence on a few West Asian countries and Nigeria. In addition the coal deposits are better than that of oil but the threat of climate change raised concern and voices from developed coal-rich countries recommending that coal exports should be abridged and yet terminated as part of mitigation tactics. So the energy security as well as climate change apprehensions necessitates shrinkage of fossil fuels consumption either through improved efficiency measures or through replacement of non-fossil fuels. Thus most of the instruments to tackle energy security anxieties also address climate change challenges since these measures obviously or indirectly diminishes the carbon intensity in the energy sector ${ }^{51}$.

\section{National Action Plan on Climate Change}

The Ministry of Environment, Forest and Climate Change is coordinating the activities of climate change related issues in India. In 2006 India espoused the National Environment Policy to furnish policy initiatives to generate awareness about climate change and facilitate capacity building for adaptation measures. The National Forest Policy also envisages dynamic projects including afforestation programmes for mounting carbon sinks via expanding forest and tree cover areas ${ }^{52}$. On 30th June 2008, Prime Minister, Dr. Manmohan Singh unveiled India's first National Action Plan on Climate Change (NAPCC) with a view to lay down the priorities and future actions of the Government for addressing climate change and updating India's national programme relevant to addressing climate change. It has outlined the existing and future policies and programs addressing climate change mitigation and adaptation $^{53}$. The Ministry of Environment, Forest and Climate Change is coordinating the programmes and policies of NAPCC and being implemented through the nodal Ministries in specific sectors or areas. Thus NAPCC renders a road map for India's climate change policy besides the overall framework for actions in diverse spheres of its energy system in response to climate change. At the same time NAPCC affirms its prominence on adaptation to climate change and economic development. The plan identifies eight core national missions as the way forward: National Solar Mission, National Mission for Enhanced Energy Efficiency, National Mission on Sustainable Habitat (public transport; building codes), National Water Mission, National Mission for Sustaining the Himalayan Ecosystem, National Mission for a Green India (afforestation), National Mission for Sustainable Agriculture and National Mission on Strategic Knowledge for Climate Change. These Missions explicitly delineated to concurrently boost India's development and climate change related goals of adaptation and GHG mitigation. Power Generation, Renewable Energy and Energy Efficiency are other ongoing initiatives of NAPCC. It can be seen that the NAPCC is an optimistic and constructive original step in India's strives to combat global climate change ${ }^{54}$.

NAPCC has recognized instruments to uphold development objectives in accordance with the overriding national priority of sustaining high economic growth rates to enhance living standards which will yield the benefits for addressing Climate Change as a spin off. The Central Government has advised State Governments to prepare State Action Plans 
on Climate Change that are aimed at building institutional capacities and implementing sectoral activities to tackle Climate Change. Hitherto, twenty one states namely Andaman and Nicobar, Andhra Pradesh, Arunachal Pradesh, Assam, Delhi, Jammu \& Kashmir, Kerala, Karnataka, Lakshadweep, Madhya Pradesh, Manipur, Meghalaya, Mizoram, Nagaland, Odisha, Punjab, Rajasthan, Sikkim, Tripura, Uttarakhand, and West Bengal have prepared a document on State Action Plan on Climate Change (SAPCC) ${ }^{55}$. The principles enunciated and the approach laid out by the National Action Plan on Climate Change will guide to three shifts in the way climate change has so far been deemed. First, it stresses qualitative changes in growth pathways rather than quantitative cutback of emissions. In fact, even developed countries couldn't concur on the base year to measure diminutions, the percentage of reductions to be induced and the quantities of carbon that can be reduced without affecting economic growth because each country focuses on the dilemma through the lens of its national industry. The plan's stress on demand-side management shifts the debate to economy-wide areas where cost effective measures can be introduced. It tries to redefine cost-effectiveness of measures in terms of opportunity costs instead of the bottom line of the industrial sector of an economy. Second is that the plan focuses on modifying activities that bring about emissions of carbon or are struck by climate change, through new knowledge. Third, under the plan adaptation to the undesirable outcomes of climate change is deemed as the policy priority. The national action plan considers that the day today decisions by individual consumers propel the economy-wide emanations of carbon dioxide ${ }^{56}$.

The Green India programme under NAPCC envisages undertaking immense afforestation of degraded forest lands in the country. Financial resources are mobilized to make funds available under Compensatory Afforestation Fund Management and Planning Authority (CAMPA). The funds are collected from the market, developing partner associations, and earnings from tree felling at ecologically suitable intervals. This programme will span around six million hectare in the country in about 10 years. So as India has also identified for early operationalization of the Adaptation Fund and Special Climate Change Fund under the United Nations Framework Convention on Climate Change for dealing with Climate Change concerns in the developing countries ${ }^{57}$. As a responsible nation, India is aware of its obligations and dedicated to the path of sustainable development. Thus India's National Action Plan on Climate Change put forward obvious directions for modifications in policy, planning and public-private partnerships at the national level. At the same time it offers a global vision for altering more prospicient trends to attain sustainable development ${ }^{58}$. The targets and the objectives of the Action Plan are intended to be accomplished through a sustainable development strategy in the coming years. Besides various thrust areas have been distinguished for this purpose and a synchronized initiative to identify Nationally Appropriate Mitigation Actions and execute them towards this goal will be taken. Climate Change Action Programme (CCAP) is the new thematic or umbrella Scheme which aims at advancing scientific research, information and assessment of the phenomenon of Climate Change, building an institutional and analytical capacity for research and studies in the area of Climate Change, and supporting domestic actions to address Climate Change through 
specific programmes and actions at the national and state level. The scheme encompasses eight activities, in which, three relate to scientific studies on Climate Change, two are speak about institution and capacity building and three others describes domestic and international actions $^{59}$.

\section{Alternative Energy Sources}

The International Energy Agency defines renewable energy as 'the energy derived from natural processes that are replenished constantly. In its various forms, it derives directly or indirectly from the sun, or from heat generated deep within the earth. Included in the definition is energy generated from solar, wind, biomass, geothermal, hydropower and ocean resources, and biofuels and hydrogen derived from renewable resources'. A change over from fossil fuels to renewable energy and nuclear power in the energy supply together with noteworthy improvements in energy efficiency and alternative mitigation choices such as carbon capture and sequestration (CCS) can add to attaining ambitious emissions cutback goals and energy security concerns across the world ${ }^{60}$. In India the environment challenges as well as energy security issues can be addressed by reducing the use of fossil fuels and transition to alternate fuels. India is endowed with diverse natural resources such as solar, wind, water and biomass which can be exploited in a copious manner to cope up with the emergent energy requirements of the coming years. But now the renewable energy development is at its infancy stage and needs a large amount of investment moreover the easy availability of coal makes it the most used energy source amid old technologies and the scarcity of Carbon Capture and Storage (CCS) capable power plants ${ }^{61 \& 62}$. To ensure energy security, to reduce the dependence on oil imports and to fulfil the commitment that India's per capita greenhouse gas emissions level never exceeds those of the developed countries at any point of time in future, it gave more emphasize on the development and deployment of alternative fuels such as hydrogen, bio-fuels, synthetic fuels and nuclear power. To increase clean power or renewable energy India opted for bio, wind, hydro, solar, geothermal and tidal energy technologies ${ }^{63}$.

India has initiated several climate-friendly measures, particularly in the area of renewable energy. As part of the prolusion of renewable energy sector, in 1992 the Indian government established the Ministry of Non-Conventional Energy Sources, which has been renamed as the Ministry of New and Renewable Energy (MNRE) in 2006. The formation of a fullfledged ministry for renewable energy was a milestone in India's history therefore it becomes the first country in the world to have a dedicated Ministry for renewable energy. MNRE's mission is to decrease India's reliance on imported oil, thereby improving the country's energy security supply; to enhance clean power's contribution to the national energy mix; to enlarge the current energy supply with an intention of ameliorating access to clean energy; and to facilitate new and renewable energy technologies to be cost-competitive. The Ministry also assists both on- and off-grid power generation from renewable sources including small hydro, wind, solar, biomass, and industrial and urban wastes ${ }^{64}$. India's 
response to climate change is multi-dimensional which facilitates the country to progress persistently towards a low-emission path and sustainable energy growth. This comprises shift in general consumption trends, an urge for the utilization of renewable energy sources as well as better energy efficiency, a transport policy that aims to promote a well-organized rail-road mix as well as developing a competent highways network, an automobile policy that is lined up to the finest international safety and emission standards, promoting clean coal technologies as well as low carbon intensive fuels for transport and urban planning that seeks to maximise living and working spaces plus renovate dwindling green cover. Now a days, India is playing a leading role in the identification, development and utilization of new and renewable energy sources ${ }^{65 \& 66}$.

In India, harnessing of splendid renewable energy sources are expected to play a crucial role in diversifying the fuel basket, enhancing energy security, addressing environmental concerns, increasing access to energy sources, greening the energy sector and leading the massive market for renewable energy. At the same time the development of renewable energy sources which are indigenous can increase energy security by diversifying supply, reducing import dependence, and mitigating fuel price volatility. Further, accelerating the utilization of renewable energy is also essential to meet India's commitments to trim down carbon intensity. The power sector contributes almost half of the country's carbon discharges and on an average basis, every $1 \mathrm{GW}$ of additional renewable energy capacity diminishes $\mathrm{CO}_{2}$ emanations by 3.3 million tons a year ${ }^{67 \& 68}$. But the relative high cost of generation, intermittent nature of power availability, grid connectivity issues and lack of reliable estimates are the major obstacles in front of the exploitation of renewable energy sources in the country. If these issues could be tackled, the dreams of greening the energy sector and increasing energy access could be successfully accomplished. Moreover potential R\&D and mass production of renewable energy products could reduce the cost of production from these resources ${ }^{69}$.

Today, India has a renewable power capability of over $13000 \mathrm{MW}$, which is about 8 percent of the whole installed facility in the country and adds nearly 3 percent to the electricity mix (figure 3). India ranks fourth in the world in wind power installed capacity and the foremost part of power that is about $9000 \mathrm{MW}$ comes from wind power. Private sector has the major share of investment in the installed capacity of wind power. Private developers are the chief investors in biomass power projects that have $650 \mathrm{MW}$ facility based on combustion of crop residues and agro-industrial wastes. An extra power of around 900 MW capacities has exported to the grid from private sector sugar mills through bagasse cogeneration projects. India has huge prospective for solar power generation due to the availability of high solar insulation on extensive tracts of land in arid and semi-arid regions of the country. It is estimated that solar power is expected to reach grid parity by 2015-17 against the milieu of hiking fossil fuel prices, decreasing costs and efficiency upgrading of solar power ${ }^{70}$. Solar based power technologies have great demand on the pretext of zerosum emissions and it also directs to energy security by curtailing coal and oil needs to satisfy final energy demand. In addition, just like other renewable energy technologies it can 
be used efficiently in decentralized systems, thereby limiting the demand for infrastructure investments of extending the grid out to them, dipping transmission losses, and escalating energy accessibility to the presently under served ${ }^{71}$.

As a resource, water or hydropower needs particular emphasis owing to its renewable plus non-polluting nature, high flexibility in the system operation and combust no fuel in comparison with fossil fuel plants and its price is almost insulated from inflationary pressures. The allocation of small hydro projects is about $25 \mathrm{MW}$ station capabilities which have aggregated to $2200 \mathrm{MW}$. According to the Central Electricity Authority (CEA) estimates of late 1980s, India has a fairly rich hydropower potential of $84 \mathrm{GW}$ at 60 percent load factor and only about 22 percent of this has been unfolded. So the accelerated development of the untapped resources has an extraordinary significance from an energy security perspective. It is the same in the case of climate change because it is found that usual giving out of GHGs for hydropower were still 30 to 60 times less than those from fossil-fuelled stations of the same size ${ }^{72}$. In the coming decades biofuels are expected to take part in a vital role in the quest for energy security and GHG emissions reduction. The Indian approach to biofuels is based on non-food feed stocks, which has to be extended to new areas by including degraded or wasteland not suited to agriculture hence evading a probable fuel versus food security clash while generating fresh employment opportunities in rural areas ${ }^{73}$.

Energy efficiency, demand side management, reducing energy consumption by substituting fuels as well as technologies and altering consumer behaviour are obviously the most environmentally feasible approach to deal with raises in demand for energy services. Energy efficiency can include practices such as shifting from conventional coal power plants to combined heat and power units, lowering thermostats, better maintaining industrial boilers, and walking or cycling instead of driving. These activities not only entail very little damage to the environment but also cost effective as long as they are strategically executed to avoid the bounce back consequence ${ }^{74}$. The Energy Conservation Act of 2001 and Electricity Act of 2003 are providing legal and regulatory framework for encouraging energy efficiency. The regulatory commissions are concentrating on transmission and distribution loss reduction and on benchmarking efficiency levels. In recent years, the Bureau of Energy Efficiency (BEE) has made some substantial endeavours by means of labelling of electrical appliances, ensuring mandatory audits of energy intensive industries, notification of Energy Conservation Billing Code, and so on ${ }^{75}$.

India's electricity demand is likely to augment at an average annual rate of 7.4 percent in the next 25 years. And to keep pace with its fast growing economy the generation competence will have to enlarge fivefold ${ }^{76}$. In this context, nuclear power is getting growing recognition as a green resource. There is a group of people who supports India's efforts towards increasing share in nuclear energy from the perspective of achieving long-term energy security and sustainable development. India has developed a very ambitious nuclear program to meet its energy needs as a result nuclear power becomes one of the major components in the fuel basket. It is estimated that by 2032 nuclear share may go up to 7 percent from the 
present level of approximately 3 percent $^{77}$. The 3 -stage nuclear energy programme which has devised by Homi Bhabha in 1958 is finally being pursued with vigour on multiple fronts especially with the removal of international ban on civil nuclear trade in $2008^{78}$. In the medium and long term future, nuclear energy will play a key position in India's energy development and will be indispensable from the standpoint of mitigating climate change. In the opinion of International Energy Agency, fusion energy has the potential to be a very safe, cost-effective and environmentally attractive source of power, though it warns that a considerable amount of research is yet to be realized and safety aspects of diverse fusion systems should be expanded ${ }^{79}$.

\section{India's Installed Power Generation Capacity}

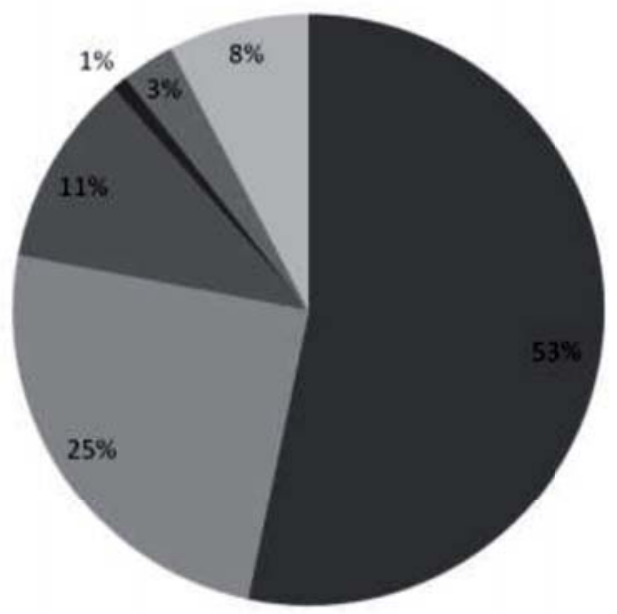

Figure 3. India's Installed Power Generation Capacity

Source. Kumar. (2012): Securing India's energy future.

The Electricity Act of 2003 along with the National Electricity Policy of 2005 (NEP) and the Tariff Policy (TP) instructs promotion of electricity generation from renewable sources. These policies visualize regulatory interventions for the encouragement of renewable energy sources $^{80}$. The ventures of the Central Electricity Regulatory Commission (CERC) vary from determination of preferential tariff for renewable energy and formulating a supportive framework of grid connectivity via the Indian Electricity Grid Code to developing marketbased mechanisms like Renewable Energy Certificate (REC). The REC instrument is perceived as the main programme towards advancing renewable energy and promoting competition in this sector. It takes in hand the dual goals of tapping renewable energy sources in areas with huge potential and abidance with Renewable Purchase Obligation (RPO) by resource-deficit states. This significant initiative was officially launched in 2010, heralding a novel epoch in the expansion of green energy in India ${ }^{81}$. 
Every energy source has some type of environmental impact even if energy efficiency practices are properly implemented in an environmentally friendly manner. At the same time renewable energy sources like wind and solar have obvious environmental gains in comparison with conventional sources as they are not free of consequences ${ }^{82}$. In the context of India a transformation in the energy diet is very important because at present virtually 80 percent of energy comes from burning of fossil fuels, which is the highest source of GHG giving off. In this scenario, renewable energy represents a win-win opportunity for India which helps to fight the adverse effects of climate change on vulnerable populations in India and ensure energy security for the whole country ${ }^{83}$. Thus India can optimally make use of renewable energy resources and be part of reenergizing the globe with clean energy.

\section{Conclusion}

All the people and every nation share the same planet i.e. our Earth hence addressing the climate turmoil by each and every one together is decisive to the human prosperity and well-being for the existing and the upcoming generations. Approach to inexpensive, clean and profuse supplies of energy is essential for building sophisticated hi-tech societies. Since industrial revolution, fossil fuels backed the unprecedented development of humanity but the urge for clean and sustainable energy production evolved subsequently with the challenges of climate change. It is a reality that even after years of discussion no country has been capable of redirecting its advancement from $\mathrm{CO}_{2}$ emissions and no country has manifested how to put up a low carbon economy. Until now, based on arguments of equity and per capita emissions India has departed from committed efforts in the universal endeavours to mitigate GHG emissions. But by being a responsible and progressive member of the international community, India demonstrated the flexibility along with other developing countries towards the endeavours to trim down climate change causalities though it prioritises the objectives of social as well as economic development and poverty eradication. Moreover at the beginning itself, India has taken strenuous efforts for achieving its vision of development amid concerns for equity and ensuring energy security along with climate change mitigation strategies.

The problems of climate change and energy security are the major obstacles for India's energy policy while they open gargantuan opportunities to shift its people to cleaner energy trajectories and know-how in the long term. It is the duty of the government to provide increasing amounts of energy to the rapidly growing populace of India in an environmentallysustainable fashion. Thus ensuring energy security through exploiting splendidly available alternate plus renewable energy sources will dwindle down the carbon footprint in the energy sector. Most of the renewable energy sources are regionally available and the utilization of these energy resources with locally-appropriate technology in a suitable and cost-effective manner offers the energy requirements of rural areas as well as national sector. Advanced countries contribution of innovative and renewable energy technologies to developing countries like India which have profuse renewable resource endowment should be the key 
in the global energy and environmental agenda. The reductions of GHG emissions add to climate change mitigation efforts. Likewise energy security and climate change strategies contributes each other in an outstanding style along with the developmental ambitions of India which is global, inclusive, cooperative, environmentally sensitive and above all scientific.

\section{End Notes and References}

1. Gangwar, S. (2013). Climate change and energy challenge: A focus on India. Advance in Electronic and Electric Engineering, 3(8), 1057-1062.

2. Economic Survey. (2012). Sustainable development and climate change. http://indiabudget.nic.in.

3. Gangwar, S. (2013). Climate change and energy challenge, 1.

4. Upadhyay, D. K. (2014). Coping with climate change: India-EU cooperation on renewable energy and clean technology. India Quarterly, 70(3), 241-256.

5. Gaan, N. (2001). Politics of governance of global climate change: Not on equity but on North's interests. India Quarterly, 57(4), 89, 112.

6. Sovacool, B. K. (2014). Environmental issues, climate changes, and energy security in developing Asia. ADB Economics Working Paper Series, No. 399, Asian Development Bank, Manila, Philippines. 7. Dril, T. V., \& Tilburg, X. V. (2011). Renewable energy: Investing in energy and resource efficiency. United Nations Environment Programme. Retrieved from www.ictom.info/.../3rd.../ ConferenceProceedings_3rd-ICTOM-2012.pdf.

8. Rastogi, N. P. (2011). Winds of change: India's emerging climate strategy. The International Spectator: Italian Journal of International Affairs, 46(2), 127-141.

9. Kumar, D. (2012). Securing India's energy future. Centre for Defence and Strategic Studies, Australian Defence College.

10. Shrimali, G., Srinivasan, S., Goel, S., Trivedi, S., \& Nelson, D. (2015). Reaching India's renewable energy targets cost-effectively. A Climate Policy Initiative (CPI) - The Indian School of Business (ISB) series. Retrieved from www.climatepolicyinitiative.org.

11. Gupta, A. K. (2008). Renewable energy development in India. India Council for Sustainable Development. Newsletter, 1, 10-12.

12. Upadhyay, D. K. (2014). Coping with climate change, 4.

13. Rajya Sabha Secretariat. (2008). Climate change: Challenges to sustainable development in India. Occasional Paper Series 3, Research Unit (Larrdis), Rajya Sabha Secretariat, New Delhi.

14. Sarkar, A. N. (2011). Global climate change and emerging environmental and strategic security issues for South Asia. Journal of Environmental Protection, 2, 1162-1171.

15. Dutt, G., \& Gaioli, F. (2007). Coping with climate change. Economic and Political Weekly, 42 (42), 4239-4250.

16. Betz, J. (2012). India's turn in climate policy: Assessing the interplay of domestic and international policy change. GIGA Research Programme: Power, Norms and Governance in International Relations, Working Papers, No 190, German Institute of Global and Area Studies, Germany.

17. Saran, S. (2009). The mitigation challenge in climate change-where do we stand? India Quarterly, 65 (4), 469-473.

18. Tollefson, J. (2015). Scientists step into assess carbon - emissions pledges. Nature, 521(7553), 504-505.

19. Gaan, N. (2001). Politics of governance of global climate change, 5 . 
20. Narain, S. (2009). A just climate agreement: The framework for an effective global deal. In Sunita Narain, Prodipto Ghosh, NC Saxena, Jyoti Parikh, \& Preeti Soni (Eds.), Climate Change: Perspectives from India. UNDP India: India.

21. Dutt, G., \& Gaioli, F. (2007). Coping with climate change, 15.

22. Laconte, P. (2011). Climate change energy shortage biodiversity loss: Overview of global, European and local policies and practices. Bonn: The Club of Rome-European Support Centre and EU Chapter.

23. Dutt, G., \& Gaioli, F. (2007). Coping with climate change, 15.

24. Desai, N. (2008). The new race: Energy and climate change. India Quarterly, 64(1-3), 106-115.

25. Panda, A. (2009). Assessing vulnerability to climate change in India. Economic and Political Weekly, 44(16), 105-107.

26. Lok Sabha Secretariat. (2013). Climate Change - India's Perspective. Members' Reference Service, Lok Sabha Secretariat, Parliament Library and Reference, Research, Documentation and Information Service (LARRDIS), No. 25.

27. Rastogi, N. P. (2011). Winds of change, no.8.

28. Desai, N. (2008). The New Race, no.24.

29. Ibid.

30. Upadhyay, D. K. (2014). Coping with Climate Change, no.4.

31. Srivastava, L. and Mathur, R. (2007). India's Energy Security. FES Briefing Paper 14, New Delhi. 32. Rana, N., Kumar, A., Syal, K. and Khan, M. A. (2010): Climate Change Mitigation in India. Mitigation and Adaptation Information Network. Development Alternatives, New Delhi.

33. Saxena, N. C. (2009). Climate change and food security in India. In Sunita Narain, Prodipto Ghosh, NC Saxena, Jyoti Parikh, \& Preeti Soni (Eds.), Climate change: Perspectives from India. UNDP India: India.

34. Sovacool, B. K. (2014). Environmental Issues, no.6.

35. Saxena, N. C. (2009). Climate change and food security in India, no.33.

36. Sovacool, B. K. (2014). Environmental Issues, no.6.

37. Rajya Sabha Secretariat. (2008). Climate Change, no.13.

38. Rana, N., Kumar, A., Syal, K. and Khan, M. A. (2010): Climate Change, no. 32.

39. Ghosh, P. (2009). Is India a solution to the problem or a problem to the solution? In Sunita Narain, Prodipto Ghosh, NC Saxena, Jyoti Parikh, \& Preeti Soni (Eds.), Climate Change: Perspectives from India. UNDP India: India.

40. Gupta, R., Shankar, H. and Joshi, S. (2011). Development, energy security and climate security: India's converging goals. Retrieved from the Center for Nonlinear Studies website: http://cnls.lanl. gov/ rajan/Gupta_orf_writeup_v9.pdf.

41. Noronha, L. (2009). Climate change and India's energy policy: Challenges and choices. In David Michel Amit Pandya (Eds.), Indian climate policy: Choices and challenges, STIMSON.

42. Ahn, S., \& Graczyk, D. (2012). Understanding energy challenges in India: Policies, players and issues. Partner Country Series, International Energy Agency, France.

43. Noronha, L. (2009). Climate change and India's energy policy, no.41.

44. Dormandy, X. (2007). Is India, or will it be, a responsible international stakeholder? The Washington Quarterly, 30 (3), 117-130.

45. Rai, V., \& Victor, D. G. (2009). Climate change and the energy challenge: A pragmatic approach for India. Economic and Political Weekly, 44(31), 78-85.

46. Mathur, R., Goldar, A., \& Madan, P. (2008). Energy transformations: opportunities, needs, and challenges for India in responding to energy security and climate change concerns. India Council for Sustainable Development. Newsletter, 1, 3-8.

47. Ahn, S., \& Graczyk, D. (2012). Understanding energy challenges in India, no.42. 
48. Prabhakar, A. C. (2004). India's energy security of supply and the gulf. India Quarterly, 60 (3), 120-171.

49. Gupta, R., Shankar, H., \& Joshi, S. (2011). Development, energy security, no.40.

50. Lok Sabha Secretariat. (2013). Climate change, no.26.

51. Noronha, L. (2009). Climate change and India's energy policy, no.41.

52. Ahn, S. and Graczyk, D. (2012). Understanding energy challenges in India, no.42.

53. Ahmed, B. (2009). Energy security: Emerging issues in the world energy market. New Delhi: Regal Publications.

54. Rai, V., \& Victor, D. G. (2009). Climate change and the energy challenge, no.45.

55. Lok Sabha Secretariat. (2013). Climate change, no.26.

56. Sanwal, M. (2008). The G-8 and India's national action plan on climate change. Economic and Political Weekly, 43(29), 17-18.

57. Rajya Sabha Secretariat. (2008). Climate change, no.13.

58. Sanwal, M. (2008). The G-8 and India's national action plan, no.56.

59. Lok Sabha Secretariat. (2013). Climate change, no.26.

60. Dril, T. V., \& Tilburg, X. V. (2011): Renewable energy, no.7.

61. Kumar, D. (2012). Securing India's energy future, no.9.

62. Gupta, A. K. (2008). Renewable energy development in India, no.11.

63. Osmani, A. R. (2014). Conventional energy to renewable energy: Perspectives for India. The NEHU Journal, XII (2), 41-60.

64. Arora, D. S., Busche, S., Cowlin, S., Engelmeier, T., Jaritz, H., Milbrandt, A., \& Wang, S. (2010). Indian Renewable Energy Status Report Background Report for DIREC 2010. NREL/TP6A20-48948, U.S. Department of Energy.

65. Kumar, S. (2008). Building a low-carbon Indian economy. Discussion Paper. Confederation of Indian Industry, Gurgaon.

66. Srivastava, L., \& Mathur, R. (2007). India's Energy Security, 31.

67. Sargsyan, G., Bhatia, M., Banerjee, S. G., Raghunathan, K., \& Soni, R. (2010). Unleashing the potential of renewable energy in India. South Asia Energy Unit. Sustainable Development Department and The World Bank, Energy Sector Management Assistance Programme.

68. Srivastava, S. P., \& Srivastava, S. P. (2013). Solar energy and its future role in Indian economy. International Journal of Environmental Science: Development and Monitoring, 4(3), 81-88.

69. Ramanathan, K. (2008). Energy security in the power sector: need for a holistic approach. India council for sustainable development. Newsletter, 1, 10-12.

70. Gupta, A. K. (2008). Renewable energy development in India, 11.

71. Noronha, L. (2009). Climate change and India's energy policy, 41.

72. Ramanathan, K. (2008). Energy security in the power sector, 69.

73. Gupta, A. K. (2008). Renewable energy development in India, 11.

74. Sovacool, B. K. (2014). Environmental Issues, 6.

75. Ramanathan, K. (2008). Energy security in the power sector, 69.

76. Schmid, G. (2011). The development of renewable energy power in India: Which policies have been effective? Working Paper Series 11103, University of Geneva.

77. Ramanathan, K. (2008). Energy security in the power sector, 69.

78. Gupta, R., Shankar, H., \& Joshi, S. (2011). Development, energy security, 40.

79. Kumar, S. (2008). Building a low-carbon Indian economy, 65.

80. Schmid, G. (2011). The development of renewable energy power in India, 76.

81. Economic Survey. (2012). Sustainable development and climate change, 2.

82. Sovacool, B. K. (2014). Environmental issues, 6.

83. Schmid, G. (2011). The development of renewable energy power in India, 76. 